\title{
Guerra Racial e Nação na Gran Colômbia caribenha, Cartagena, 1810-1832 ${ }^{1}$
}

\author{
RaceWar and Nation in Caribbean Gran Colombia, \\ Cartagena, 1810-1832
}

Marixa Lasso*

\begin{abstract}
Resumo: Enquanto que a maioria dos historiadores remete a origem das atuais relações raciais à escravidão colonial, Marixa Lasso argumenta que foi durante a Era das Revoluções das lutas anticoloniais americanas que nações com histórias semelhantes de colonialismo, escravidão e racismo desenvolveram distintos imaginários raciais modernos. Em particular, examina-se a origem da ideologia nacionalista de igualdade e harmonia racial (o mito da democracia racial, conforme a denominação do século XIX), durante as guerras de independência hispanoamericanas. Sua análise enfoca a Gran Colombia, uma das regiões-chave na luta pela independência hispano-americana, onde a guerra transformou o imaginário racial de duas maneiras. A guerra propiciou a idéia de igualdade racial unindo a força emocional do patriotismo, transformando-a numa ideologia nacionalista que transcendia diferenças partidárias e regionais. Ao mesmo tempo, o fantasma de outro tipo de guerra, a "guerra de raças", criou diferenças fundamentais entre o que se constituía como um discurso racial legítimo e um discurso racial ilegítimo. $\mathrm{O}$ medo da guerra de raças restringiu as ações políticas dos afro-descendentes e limitou suas oportunidades para denunciar a permanência de persistentes preconceitos e padrões de discriminações informais.
\end{abstract}

Palavras-chave: Nacionalismo, Relações étnicas, Guerras de independência - 18101824, Cartagena-Colômbia

Abstract: While most historians trace the origins of modern race relations to colonial slavery, Lasso argues that it was during the anticolonial struggles in the Americas during of the Age of Revolution that nations with similar histories of colonialism, slavery, and racism developed divergent national racial

* Associate Professor of Latin American History, Departament of History, Case Western eserve University. E-mail: marixa.lasso@case.edu.

1 Este artigo é uma tradução resumida de "RaceWar and Nation in Caribbean Gran Colombia, Cartagena 1810-1832" American Historical Review, 111, n. 2 (2006): 336-361. Tradução: Bruno Henz Biazetto. 
imaginaries. In particular, she examines the emergence of a nationalist ideology of racial harmony and equality - the twentieth-century myth of racial democracy during the Spanish American wars of independence. Her analysis focuses on Gran Colombia, one of the key sites of the struggle for Spanish American independence, where war shaped racial imaginaries in two ways. War infused racial equality with the emotional strength of patriotism, transforming it into a nationalist ideology that transcended partisanship and regional differences. At the same time, however, the phantom of another type of war, "race war," set the boundaries separating legitimate from illegitimate racial discourse. The fear of racial war restricted the political actions of people of African descent, limiting their opportunities to denounce persistent patterns of informal discrimination and prejudice.

Keywords: Nationalism, Ethnic relations, War of Independence-1810-1824, CartagenaColombia.

Durante a Era das Revoluções, as nações americanas enfrentavam o dilema de como conciliar escravidão e discriminação racial com a ideologia liberal iluminista da cidadania. A escravidão poderia ser abolida? Poderiam todos os homens livres, independentemente da sua raça, usufruir de direitos iguais de cidadania e, caso isso não ocorresse, como que a exclusão seria justificada dentro de uma ideologia que apregoava a igualdade e a fraternidade da raça humana? De 1810 até 1812, os movimentos patrióticos em toda a América espanhola responderam a última questão com uma declaração de igualdade legal e racial para todos os cidadãos livres e com a construção de uma ideologia nacionalista baseada na harmonia racial - o que estudiosos contemporâneos chamam de o mito da democracia racial. ${ }^{2}$ No México, o líder rebelde Miguel Hidalgo proclamou o fim das distinções raciais. ${ }^{3}$ $\mathrm{Na}$ Venezuela, a Constituição de 1811 decretou a revogação de "las leyes antiguas que imponían degradación civil a una parte dela población de Venezuela conocida hasta ahora bajo la denominación de pardos; estos quedan... restituidos a los imprescriptibles derechos que les corresponden como a los demás ciudadanos."4 Mais ao sul, a junta revolucionária de Buenos Aires condenou preconceitos coloniais, aos quais uma população "numerosa" e "capaz" havia sido submetida apenas por causa da cor de

2 Utilizo o termo harmonia racial, porque reflete de uma forma mais precisa a linguagem do século XIX do que democracia racial, um termo concebido posteriormente. Richard Graham (ed.) The Idea of Race in Latin America, 1870-1940. Austin: 1990.

3 Citação retirada de George Reid Andrews, Afro-Latin America 1800-200. New York: 2004, 87.

4 La constitución federal de Venezuela de 1811 y documentos afines, preliminary study by C. Parra Pérez Caracas: 1959, 205. 
sua pele. ${ }^{5} \mathrm{Na}$ época em que as guerras de Independência acabaram, em 1824, uma ideologia racial e nacionalista declarou que discriminação racial - e a identidade racial - desagregadora e antipatriótica havia surgido. Em contraste a isso, o nacionalismo estadunidense no século XIX estava centrado nas ideologias do Destino Manifesto e da supremacia da raça branca. ${ }^{6} \mathrm{O}$ que explica essa diferença?

O presente artigo argumenta que as guerras revolucionárias foram cruciais para a construção desses imaginários raciais nacionais, e que qualquer análise histórica de caráter comparativo das raças nas Américas precisa levar em consideração o importante papel das lutas anticoloniais na formação das modernas relações de raça e de identidade racial nas Américas. ${ }^{7}$ A literatura mais recente sobre a era revolucionária chamou atenção para a importância deste período na constituição da identidade nacional. Contudo, nós ainda não temos um estudo comparado das relações raciais que explore por que sociedades com um passado colonial similar de escravidão e preconceito racial desenvolveram imaginários nacionais tão distintos no que diz respeito à questão racial durante o final do século XVIII e o começo do século XIX. Isso, em parte, é derivado da tendência que os historiadores estadunidenses e latino-americanos têm de pressupor que o passado colonial das suas regiões naturalmente redundou na sua identidade racial moderna. Ainda assim, como David Brion Davis já havia percebido em 1966,

as diferenças entre a escravidão na América Latina e nos Estados Unidos não foram tão grandes em relação às diferenças regionais e temporais dentro dos próprios países em questão. A servidão do negro foi um fenômeno único, ou Gelstat, cuja variação foi menos significativa do que os usualmente subestimados padrões de unidade. ${ }^{8}$

Trinta anos depois - resumindo diversos estudos acadêmicos sobre a escravidão nos Estados Unidos e no Brasil -, Anthony Marx conclui que existe pouco no passado colonial de ambos que explique

5 George Reid Andrews. The Afro-Argentines of Buenos Aires, 1800-1900. Madison: 1980, 59.

6 Reginald Horsman, Race and Manifest Destiny: the Origins of American Racial AngloSaxonsism. Cambridge: 1981.

7 Benedict Anderson. Imagined Communities: Reflections on the Origin and Spread of Nationalism. London: 1991; Lynn Hunt, Politics, Culture, and Class in the French Revolution. Berkeley: 1984; David A. Bell "The Unbearable Lightness of Being French: Law, Republicanism and National Identity at the End of the Old Regime," American Historical Review (hereafter AHR) 106, no. 4 (2001): 1215-1235.

8 David Brion Davis. The Problem of Slavery in Western Culture. Ithaca: 1966, 229. 
trajetórias tão distintas no que diz respeito à moderna relação racial que eles possuem. ${ }^{9}$ Realmente, quando uma experiência colonial é confrontada com a outra, os imaginários raciais divergentes dos Estados Unidos e da América Latina não parecem tão naturais. Apesar de não ser uma análise comparativa, este artigo examina a construção de uma identidade racial colombiana, contrapondo esta com as origens da experiência estadunidense, argumentando que a democracia racial não era inevitável e tão pouco oriunda de um legado colonial.

A falta de um diálogo entre a literatura sobre o nacionalismo durante o período revolucionário e a literatura sobre relações de raça comparadas deriva, em grande parte, da natureza da historiografia que trata das guerras de independência na América espanhola (1808-1824). Até recentemente, os historiadores têm desprezado a importância social desse período, argumentando que as novas noções republicanas de cidadania trouxeram a ilusão de mudança; enquanto isso, deixavam estruturas sociais intocadas. ${ }^{10}$ Diversos estudos das relações de raça seguiram essa premissa. Contudo, os trabalhos de John Lynch, Winthrop R. Wright, George Reid Andrews e Aline Helg, entre outros, reconheceram a presença de uma retórica de igualdade racial entre os patriotas, mas esses mesmos trabalhos ainda não analisaram as características ideológicas ou tentaram explicar por que ou como isso surgiu. ${ }^{11}$ Essa desatenção em grande parte é derivada da noção que a igualdade racial não passava de uma retórica vazia, que apenas servia a necessidade da elite em atrair a população negra para o seu lado durante a guerra. A retórica vazia parecia ter sido confirmada pelo fato de que a escravidão permaneceu legal em grande parte da América espanhola até 1850. Acrescentando o insulto, a injúria, as declarações nacionalistas de igualdade racial permitiram à elite a manutenção de padrões informais de discriminação, ao impedir a formação de associações políticas baseadas racialmente, que foram declaradas desnecessárias, desagregadoras e

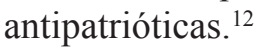

9 Anthony Marx. Making Race and Nation: a Comparison of South Africa, the United States, and Brazil. (Cambridge, 1998), 10.

${ }^{10}$ Victor M. Uribe, “The Enigma of Latin American Independence," Latin American Research Review, 32 n. 1 (1997): 236-255.

${ }^{11}$ John Lynch. The Spanish American Revolutions 1808-1826. New York, 1986 2d ed., 211212; Winthrop R. Wright, Café con Leche: Race, Class, and National Image in Venezuela. Austin: 1990, 13-42; George Reid Andrews, The Afro-Argentines of Buenos Aires, 42-63; Jaime Rodriguez, The Independence of Spanish America. Cambridge: 1998,115-116. Eric Van Young, The Other Rebellion: Popular Violence, Ideology and the struggle for Mexican Independence, 1810-1821. Stanford: 2001, 4.

${ }^{12}$ Richard Graham (ed.). The Idea of Race in Latin America. 
Uma análise mais atenta desse período nos revela, entretanto, que o ideal de igualdade racial não seria facilmente atingido. A bibliografia atual sobre as guerras de independência na América espanhola tem mostrado que as mudanças políticas desse período foram resultado de sérios debates intelectuais e políticos, que foram percebidos pelos protagonistas como mudanças que desafiavam tradições culturais entrincheiradas, bem como hierarquias sociais. ${ }^{13}$ Os trabalhos de Peter Guardino, Afonso Munera e Peter Blanchard também têm nos ensinado que latino-americanos de origem africana não foram apenas "bucha de canhão", mas que participaram e influenciaram debates políticos sobre cidadania durante o período revolucionário, às vezes pressionando as elites a concederem medidas raciais que não haviam sido inicialmente contempladas. ${ }^{14}$ Quando esta abordagem é aplicada ao mito da harmonia racial, se torna evidente que não havia nada de previsível ou sereno relacionado ao processo de construção de mitos. Primeiramente, não havia consenso imediato no que dizia respeito à igualdade racial. Não apenas a elite criolla tinha que superar uma tradição colonial que ligava ordem social a hierarquia racial, mas eles tinham também que declarar igualdade racial sem ter nenhum exemplo bem sucedido para seguir. Como os oponentes da igualdade racial no período argumentavam, os EUA haviam demonstrado que uma república moderna poderia coexistir com a escravidão e desigualdade social. ${ }^{15}$

13 Antonio Annino (ed.). Historia de las elecciones en Iberoamérica, siglo XIX. Mexico: 1995; David Brading. The First America: the Spanish Monarchy, Creole Patriots, and the Liberal State, 1492-1867. Cambridge: 1991; François-Xavier Guerra. Modernidad e Independencias: ensayos sobre las revoluciones hispánicas. Madrid: 1992; Manuel Chust. La cuestión nacional americana en las Cortes de Cádiz (1810-1814).Valencia: 1999; Anthony Pagden. Spanish Imperialism and thePolitical Imagination, 1513-1830. New Haven: 1990, 133-153; Eduardo Posada-Carbó (ed.). Elections Before Democracy: the History of Elections in Europe and Latin America. London:1996; Jaime Rodríguez. The Independence of Spanish America. Cambridge: 1998; Victor M. Uribe-Uran. Honorable Lives: Lawyers, Family, and Politics in Colombia, 1780-1850. Pittsburgh: 2000.

14 Alfonso Múnera. "Failing to Construct the Colombian Nation: Race and Class in the Andean Caribbean Conflict, 1717-1816" (Ph.D. diss., University of Connecticut, 1995); Peter Guardino, Peasants, Politics, and the Formation of Mexico's National State. Stanford: 1996; Peter Blanchard, "The Language of Liberation: Slave Voices in the Wars of Independence," Hispanic American Historical Review 82, n. 3 (2002): 499-523. Ver também George Reid Andrews, The Afro-Argentines of Buenos Aires, 42-113; Seth Meisel, "From Slave to Citizen-Soldier in Early Independence Argentina," Historical Reflections, 29, n. 1 (2003): 65-82. Para o Brasil, ver: Hendrik Kraay, “As Terrifying as Unexpected:' The Bahian Sabinada, 1837-1838" HAHR 72, n.4 (1992): 501-526.

15 September 7, 1811, in Diario de Sesiones de las Cortes Generales y Extraordinarias vol. 3. Madrid: 1870, 1796; July 31, 1811, Libro de Actas del Supremo Congreso de Venezuela, 1811-1812. Caracas: 1959, 254. 
E, na mente de muitos dos criollos brancos, a igualdade racial estava associada com o Haiti revolucionário, dificilmente uma imagem positiva para eles. Em segundo, as relações de raça no início das repúblicas estavam carregadas com uma carga de tensão muito profunda. Ao final da guerra de independência, com a emergência de uma classe política e militar negra bastante poderosa - incluindo generais, congressistas e senadores - e o direito de voto concedido para alguns segmentos da população negra e livre, os pardos desenvolveram novas expectativas em relação às possibilidades de igualdade e liberdade e exerceram uma pressão política que a elite criolla não podia ignorar. O futuro político das relações sociais e raciais era incerto e, como poderemos ver, falar de guerra racial e conspiração racial havia se tornado uma parte integral do imaginário político do período. Visto dessa perspectiva, se tornava claro que o futuro das relações de raça era um dos temas mais controversos e propensos a problemas no período da independência, e o mito da harmonia racial um dos legados políticos mais importantes da era revolucionária. De fato, se levanta a questão se a proeminência do caso dos Estados Unidos tem obscurecido os movimentos coloniais na América francesa e espanhola na formação da noção moderna de igualdade racial e cidadania. ${ }^{16}$

A pobreza dos estudos comparativos sobre raça durante o período revolucionário é também um produto da tendência dos historiadores em se focarem na escravidão colonial ou nas relações de raça do século XX. Até mesmo os trabalhos recentes de Anthony Marx e Rebecca Scott sobre sociedades pós-emancipação tendem a analisar o final do século XIX - a Reconstrução (1866-1877), as Guerras Cubanas de Independência (1865-1898) e a Abolição Brasileira (1888). ${ }^{17}$ Este foco, que reflete o peso e a riqueza dos trabalhos acadêmicos no Brasil, em Cuba e nos Estados Unidos, tem apresentado a tendência de deixar de lado as lutas

${ }^{16}$ David Geggus, "Racial Equality, Slavery, and Colonial Secession during the Constituent Assembly," AHR 94, n. 5 (1989): 1290-1308; Laurent Dubois, A Colony of Citizens: Revolution and Slave Emancipation in the French Caribbean, 1787-1804. Chapel Hill: 2004; Michel-Rolph Trouillot. Silencing the Past: Power and the Production of History. Boston: 1996.

${ }^{17}$ Thomas C. Holt; Rebecca J. Scott. Beyond Slavery: Explorations of race, labor, and citizenship in postemancipation societies. University of North Carolina Press: Chapel Hill, 2000. Ver também: George Reid Andrews, "Brazilian Racial Democracy, 1900-1990: An American Counterpoint." Journal of Contemporary History 31 (1996): 3, 483-507; Thomas Skidmore, "Racial Mixture and Affirmative Action: The Cases of Brazil and the United States" in American Historical Review 108, n. 5 (2003): 1391-1396; Darién Davis, Slavery and Beyond: The African Impact on Latin America and the Caribbean. Wilmington, Del., 1995. 
anticoloniais do período revolucionário. Estudos sobre a história do mito da democracia racial na América espanhola normalmente inicia com o libertador cubano Jose Marti e o seu chamado por uma república "Con todos y para todos" nos anos de $1890 .{ }^{18}$ Ainda assim, na América Latina, este mito emergiu entre as décadas de 1810 e 1820 , durante a guerra de independência na América espanhola. De fato, quando os libertadores cubanos fizeram da igualdade racial um slogan fundamental do grupo patriota, eles não estavam inventando um conceito novo, mas estavam construindo sobre uma tradição da América espanhola que já estava fortemente constituída, ligando o nacionalismo patriótico com igualdade racial. Ao posicionarmos as origens do mito da democracia racial algumas décadas antes do anteriormente convencionado, resulta em algo muito maior que simplesmente um ajuste cronológico pode sugerir; isso condiciona a natureza das perguntas e das respostas nas pesquisas desta área. Isso significa modificar o questionamento de como o mito da democracia racial funcionava quando foi estabelecida para, ao invés disso, de como ela foi criada. ${ }^{19}$

Esse artigo olha para a construção do mito da harmonia racial ao examinar o relacionamento entre raça, guerra e nação através de duas perspectivas diferentes. A primeira parte examina como durante as guerras de independência a igualdade racial evoluiu de uma crença compartilhada por alguns radicais americanos e espanhóis para uma construção patriótica e nacionalista que fazia uma perfeita distinção entre igualdade patriótica e desigualdade espanhola. A segunda parte do artigo examina a emergência do fantasma da guerra entre raças e o seu impacto na construção do ideário racial. Especificamente, é analisado como demonstrações explícitas de descontentamento racial se tornaram sinônimo de divisão antipatriótica. Esse artigo argumenta que este segundo processo não foi um corolário do primeiro, bem como a ligação entre igualdade racial e nacionalismo por si só não exclui as expressões deste descontentamento. O ideal de harmonia racial e

${ }_{18}$ Alejandro de la Fuente. A Nation for All: Race, Inequality, and Politics in Twentieth-Century Cuba. Chapel Hill: 2001; Ada Ferrer. Insurgent Cuba: Race, Nation, and Revolution, 1868-1898. Chapel Hill: 1999; Aline Helg, Our Rightful Share: The Afro-Cuban Struggle for Equality, 1886-1912. Chapel Hill, 1995. De modo análogo ${ }_{2}$ Emilia Viotti da Costa remete as origens do mito da democracia racial aos anos 1930. Emilia Viotti da Costa, The Brazilian Empire: Myths and Histories. Chapel Hill: 2000, 234-246

${ }_{19}$ Rebecca J. Scott, "Fault Lines, Color Lines, and Party Lines: Race, Labor, and Collective Action in Louisiana and Cuba, 1862-1912," in Beyond Slavery, 61-106. Nancy P. Appelbaum, Anne S Macpherson, and Karin Alejandra Rosemblatteds. Race and Nation in Modern Latin America. Chapel Hill: 2003. Existe uma imensa e rica literatura sobre identidades raciais modernas que não pode ser incluída no espaço deste ensaio. 
igualdade tinha o potencial tanto de dar mais poder para os que não possuíam o direito de voto, bem como mantê-los em seus devidos lugares. O questionamento era o que controlava o conceito? A resposta não era imediata, mas era por si mesma produto da contestação de como os pardos buscavam demonstrar o seu descontentamento racial com o objetivo de atingirem a igualdade racial, enquanto as elites criminalizavam esse descontentamento, afirmando que este ideal já havia sido atingido.

O foco regional deste ensaio é a província de Cartagena, na Colômbia caribenha. Cartagena foi um teatro crucial das lutas de independência, nas quais o povo de origem africana - que representava a maioria demográfica - teve um papel essencial no plano político e militar. Durante grande parte do período analisado por este artigo, ela era parte de um território maior que a Colômbia do período. Ao final do período colonial, Cartagena era parte do vice-reinado de Nova Granada, que incluía o atual território da Colômbia, Equador, Panamá e Venezuela, que naquele tempo incluíam as regiões administradas pelo velho vice-reinado de Nova Granada, o qual os historiadores atualmente chamam de La Gran Colombia. Portanto, a formação do imaginário racial em Cartagena estava ligada com esta área maior. Colombianos se uniram aos venezuelanos no exército patriótico, onde a movimentação interna entre as duas regiões era intensa. Parecida com a Venezuela, em Cartagena a lealdade - ou a falta de - do povo de origem africana foi vital para o sucesso ou o fracasso do exército patriótico e, como na Venezuela, a Colômbia caribenha contribuiu com alguns dos oficiais e heróis na época da Independência. ${ }^{20}$

Um dos aspectos mais fascinantes da declaração de igualdade racial dos colombianos para todos os cidadãos livres foi como tão rapidamente se tornou um elemento essencial do patriotismo colombiano, particularmente considerando que nas últimas décadas de mando colonial havia pouco na atitude dos brancos que escondesse o papel crucial que a igualdade racial teria no nacionalismo patriótico. A maioria dos criollos brancos não estava muito inclinada a renunciar aos seus tradicionais privilégios raciais e estava fortemente contra a pequena reforma promovida pelos Bourbons a favor dos povos de origem africana. As demandas dos pardos por um grau maior de

\footnotetext{
${ }^{20}$ German Carrera Damas. Boves: Aspectos Socioeconómicos de la guerra de independencia. Caracas: 1968; Eleazar Córdova Bello, La independencia de Haiti y su influencia en Hispanoamérica (Caracas, 1967); Francisco Zuluaga, Guerrilla y Sociedad en el Patía (Cali, 1993).
} 
inclusão social geralmente possuíam o apoio dos oficiais peninsulares que valorizavam a contribuição econômica e militar dos pardos para a coroa, comparando a sua obediência e lealdade com a arrogância e o descontentamento dos criollos brancos. Em Cartagena, os criollos brancos lutaram contra a decisão da coroa de conceder as milícias negras os privilégios legais corporativos dos militares e, também, se opuseram as tentativas dos pardos ricos de entrarem em profissões proibidas para cidadãos que não eram brancos. ${ }^{21} \mathrm{Um}$ dos exemplos mais eloqüentes de sua oposição era o Conselho Municipal de Caracas, que realizou um protesto memorial contra a publicação em 1795 do chamado "Gracias al Sacar", um procedimento legal que permitia a população de origem africana comprar o direito ao status de um branco. ${ }^{22}$ Como, o Conselho Municipal questionava, poderia um branco, cuja família manteve cuidadosamente a sua limpeza geração após geração, ser igual a um pardo que era maculado pela escravidão e ilegitimidade? O Conselho ponderava sobre a necessidade de manter os pardos na sua presente condição de subordinação, sem nenhuma lei que porventura os misturasse com os brancos. De acordo com o Conselho Municipal, o decreto da coroa só poderia ser resultado de relatórios falsos e mal informados dos oficiais espanhóis nas Américas, que não se importavam com os interesses os españoles americanos. ${ }^{23}$

Inspirados pela revolução francesa e haitiana, alguns criollos brancos começaram a questionar a funcionalidade de hierarquias raciais tão arraigadas. Um dos homens mais instruídos do vice-reinado, o rico e poderoso "cartagenero" Ignácio Pombo, buscava evitar um cenário semelhante ao ocorrido no Haiti, quando propôs a abolição da escravatura e a eliminação de distinções raciais entre as classes mais baixas (mas mantendo os privilégios tradicionais da nobreza). ${ }^{24} \mathrm{Em}$ um gesto mais radical, em 1797, uma conspiração republicana multiétnica na cidade portuária de La Guairá vislumbrava uma nação sem distinção racial. Seus decretos aboliam a escravidão e declaravam: "La igualdad natural entre

\footnotetext{
${ }^{21}$ Allan Kuethe. "The Status of the Free Pardo in the Disciplined Militia of New Granada" Journal of Negro History 56 (1971): 105-117; Allan Kuethe, Military Reform, 165-183 e Archivo General de Simancas, Secretaría de Guerra, 7069, Exp. 36-1, fols.1-6; Alfonso Múnera, "Failing to Construct the Colombian Nation," p. 112

${ }^{22}$ Magnus Mörner, Race Mixture in the History of Latin America. Boston: 1967, 60-70.

23 "Informe que el Ayuntamiento de Caracas hace la Rey de España referente a la Real Cédula de 10 febrero de 1795" 28 de noviembre de 1796". In: José Félix Blanco (ed.) Documentos para la historia de la vida pública del Libertador. Caracas: 1875-78, 292, 293.

24 José Ignacio de Pombo. Comercio y contrabando en Cartagena de Indias. Bogotá: 1986. Originally written in June 2, 1800, p. 57-58.
} 
todos los habitantes de las provincias y distritos y se encarga que entre blancos, indios, pardos y morenos reine la mayor armonia." ${ }^{25}$ Apesar da íntima ligação entre igualdade racial e patriotismo republicano presentes neste documento se tornariam posteriormente o esteio da retórica patriótica racial, é necessário ser enfatizado que em 1797 esta retórica ainda pertencia apenas a um imaginário político marginal. Da mesma forma que a revolta de escravos haitiana do período, esta conspiração foi combatida com uma repressão exemplar, e grande parte dos criollos brancos não flertava com essa visão de igualdade racial. ${ }^{26}$

Entre 1810 e 1821, uma ideologia crítica e de mudança política marcou o Império Espanhol. A cidadania para pessoas de origem africana não era mais apenas a meta de alguns poucos radicais espanhóis e americanos, ela se tornou um dos temas principais da discórdia entre espanhóis e americanos. De agora em diante, os patriotas alegavam ser os únicos apoiadores da igualdade racial, portanto ligando igualdade e harmonia racial com o nacionalismo americano. O que catalisava essa mudança foi a invasão napoleônica, em 1808, e o conseqüente aprisionamento do rei Fernando VII, que gerou uma crise de legitimidade que iria eventualmente redundar na independência da América espanhola Continental por volta de 1824. De especial importância para a consolidação da igualdade racial como um elemento do patriotismo nacionalista foi o chamado das Cortes em Cádiz, onde os representantes de todo império se encontrariam de 1810 até 1814 para elaborarem uma constituição moderna para o Império Espanhol. Entre as profundas transformações aprovadas em Cádiz, a reestruturação do pacto colonial era de especial importância para as relações de raça na América espanhola. ${ }^{27}$ Teriam os americanos os mesmos direitos a representação que os espanhóis? A resposta para esta pergunta logo adquiriu implicações raciais, como, por exemplo, a proporção de representantes americanos que dependiam se os índios, negros e mestiços seriam contabilizados como cidadãos. Mesmo que os representantes espanhóis tenham logo

\footnotetext{
25 "Ordenanzas de la Conspiración de Gual y España". In: Pedro Grases, La Conspiración de Gual y España y el Ideario de la Independencia. Caracas: 1996, 175-176.

${ }^{26}$ Archivo General de Indias, Estado, 53, no, 77, fol.1-2; Allan Kuethe. Military Reform and Society, 141-143; Aline Helg, "A Fragmented Majority: Free "Of All Colors," Indians, and Slaves in Caribbean Colombia During the Haitian Revolution”. In: David Geggus (ed.). The Impact of the Haitian Revolution in the Atlantic World. Columbia SC.: 2001. Para Venezuela, ver: Federico Brito Figueroa. Las insurrecciones de los esclavos negros en la sociedad colonial venezolana. Caracas: 1961, 72-76; Pedro M. Arcaya. Insurrección de los negros de la Serranía de Coro. Caracas: 1949.

${ }_{27}$ Manuel Chust. La cuestión nacional americana. 32, 52.
} 
decidido dar a cidadania para os índios, eles se recusaram a proporcionála para os negros, teoricamente excluído das castas (mestiços livres) que constituíam a maioria da população americana.

$\mathrm{O}$ elo entre a representação americana e o direito de cidadania das pessoas de origem africana traria graves e inesperadas conseqüências. A defesa da cidadania dos pardos forçou os deputados americanos a desafiarem as tradicionais justificativas para hierarquias raciais ao exaltarem a contribuição dos pardos para a nação e para provarem que a harmonia, e não o conflito, caracterizava a região racialmente heterogênea. Por exemplo, alguns deputados americanos superaram a maldição da ilegitimidade que tradicionalmente caracterizava $o$ discurso sobre os povos de origem racial mista ao retratarem as relações sexuais inter-raciais como a prova viva da harmonia inter-racial. ${ }^{28}$ Outros exaltaram longamente o suor dos pardos como agricultores, a sua contribuição como artesãos e o seu papel indispensável como milicianos. ${ }^{29} \mathrm{Um}$ deputado chegou até mesmo ao ponto de dizer que "las castas eran las depositarias de toda la felicidad americana." ${ }^{30}$ Estes debates tiveram repercussão em todo mundo hispânico através de jornais locais que cobriram esses eventos, enfatizando a recusa dos espanhóis em conceder aos americanos a igualdade no que dizia respeito ao direito de representação. ${ }^{31}$

O que fez de Cádiz um momento marcante para a história das relações raciais na modernidade da América espanhola é que a igualdade racial se tornou emocionalmente ligada ao patriotismo americano no Novo Mundo. Mas não pretendemos dizer com isso que sem Cádiz os patriotas não teriam concedido igualdade legal para os povos de origem africana, mas que por causa de Cádiz os americanos aprenderam a fazer a ligação entre patriotismo e igualdade racial, e, ao mesmo tempo, associaram a opressão espanhola à idéia de desigualdade racial. Tivessem as Cortes concedido os direitos de cidadania aos povos de

${ }^{28}$ September 6,1811, Diario de Sesiones, 3, 1789-1790.

${ }^{29}$ September 7, 1811, Diario de Sesiones, 3, 1799. Manuel Chust, La cuestión nacional, p. 153-15.

30 "Carta 6 de Juan Sintierra sobre un artículo de la Nueva Constitución de España". El Español, October 30, 1811.

${ }^{31}$ Periódicos - particularmente El Español, com sede em Londres - foram cruciais na formação da opinião pública esses debates. Jaime Rodriguez, The Independence of Spanish America, 82-103; François Xavier Guerra. Modernidad e Independencias; David Brading, The First America, 573-577. For Cartagena, Alfonso Múnera has noticed that in 1811 Cartagena, the newspaper El Argos Americano reproduced fragments of El Español coverage of the Cádiz debates. "Failing to Construct the Colombian Nation," 237. 
origem africana, a igualdade racial poderia muito bem ter se tornado um tema capaz de dividir Liberais e Conservadores, independentemente da nacionalidade. Porém, os espanhóis decidiram não conceder tais direitos, o que criou um claro contraste entre eles e os americanos nesse assunto. Portanto, os patriotas poderiam clamar para si próprios o status de únicos defensores da igualdade racial. O que começou como uma tática para assegurar mais representantes, havia se tornado uma poderosa construção nacionalista, que combinava igualdade racial com todo apelo emocional do nacionalismo patriótico que estava acima das diversas minúcias existentes entre o debate político e a oposição. ${ }^{32}$

Enquanto representantes debatiam em Cádiz, os pardos e a elite criolla se juntaram para deporem as autoridades espanholas. Em Cartagena, da mesma forma que em outras cidades da América espanhola, a crise de legitimidade do império levou a uma luta entre os espanhóis e os criollos pelo controle do governo local. Nas regiões onde os pardos eram a maioria da população, tanto os espanhóis como os criollos estavam bastante cientes da importância do seu apoio. Por exemplo, na cidade de Cartagena, artesãos pardos e criollos brancos depuseram autoridades espanholas em nome do povo e estabeleceram uma junta patriótica. ${ }^{33}$ Sem esperar pela legislação de Cádiz, as instruções eleitorais em Cartagena incluíam todas as raças em condição de igualdade já em dezembro de 1810. As instruções estabelecidas para as eleições "todos los vecinos de los distritos de las parroquias, blancos, indios, mestizos, mulatos, zambos y negros, con tal que sean padres de familia, o tengan casa poblada y que vivan de su trabajo". ${ }^{34}$

Em outras localidades, a aliança entre pardos e patriotas teve de esperar um pouco mais. No crucial teatro de guerra de Los Llanos, os pardos inicialmente se juntaram aos espanhóis, seus aliados tradicionais contra as elites locais. Contudo, até 1816, a maioria dos llaneros havia mudado para o lado dos patriotas. Entre as razões que motivaram essa

32 Análise de documentos em maior detalhe em: Marixa Lasso. "A Republican Myth of Racial Harmony: Race and Patriotism in Colombia, 1810-1812". Historical Reflections 29, n. 1 (2003): 43-63.

${ }^{33}$ Marixa Lasso "Revisiting Independence Day: Afro-Colombian Politics and Patriot Narratives, Cartagena, 1809-1815". In: After Spanish Rule: Postcolonial Predicaments of the Americas. Mark Thurner and Andres Guerrero (ed.). Durham: Duke University Press, 2003.

34 "Instrucciones que deberán observarse en las elecciones parroquiales, en las de partido y en las capitulares, para el nombramiento de diputados en la Suprema Junta de la provincia de Cartagena, 11 December 1810." Efemérides y anales del Estado de Bolívar, Manuel Ezequiel Corrales (comp.) Bogotá: 1889. Vol. 2: 48. 
mudança, estava uma troca na liderança espanhola que encerrou o perfil populista existente no início do processo e a emergência de uma liderança popular patriota que incluía mestiços e pardos como Jose Manuel Piar e Jose Antonio Paez. Igualmente importante foi o uso efetivo da rejeição da cidadania aos pardos, por parte dos espanhóis, na propaganda patriota. ${ }^{35}$ Efetividade deste argumento se tornou aparente para um oficial espanhol visitando as tropas dos patriotas do General Paez, em 1820, que lhe informaram que uma das razões listadas pelos soldados para se juntarem aos patriotas foi a de que a Constituição espanhola "no es del todo lisonjera mediante a no considerarse como ciudadanos a los originários de África." ${ }^{36}$ No período, o conceito de igualdade racial estava firmemente estabelecido no lado patriótico. Os discursos dos patriotas deste momento lembravam aos soldados negros de como "Espana [otorgo] sus derechos a los blancos, pero negandolos enteramente a los hombres" e os convidou para que "unamonos todos, dando de este modo al mundo de Europa un ejemplo de fraternidad." 37

Nos anos seguintes a Independência, o novo governo colombiano expandiu e popularizou ainda mais noções de uma harmonia racial americana através de cerimônias públicas, artigos de jornal, normas jurídicas e debates no congresso. Similar ao mito atual de democracia racial, as primeiras noções republicanas de democracia racial atrelavam identidade nacional a igualdade e a harmonia racial. Contudo, as bases ideológicas dessa noção nacionalista foram moldadas por valores políticos desse período e eram relativamente diferentes dos verificados no século XX. Primeiramente, a tolerância racial peninsular não foi apresentada como um precedente histórico para a harmonia racial colombiana. Muito pelo contrário, a Lenda Negra, que caracterizava o jugo espanhol como tirânico e obscurantista, foi crucial para os primeiros republicanos no estabelecimento de um discurso racial. A Lenda Negra permitiu o desaparecimento dos conflitos raciais entre os americanos, onde todos se tornaram vítimas da tirania espanhola. Isso também permitiu aos

\footnotetext{
${ }^{35}$ James King, "A Royalist View of the Colored Castes in the Venezuelan Wars of Independence," HAHR 33, n. 4 (1953): 527-537.

36 "Declaración de los capitanes Don Juán Jaldon y Don Andrés Maria Alvarez sobre lo ocurrido en su enviada a San Juan de Pyra para tratar con el Jefe disidente Paez," 5 August 1820, AGI, Indiferente, 1568.

37 "Proclama de José Francisco Bermúdez," Cartagena, August 8, 1815, Archivo Histórico Nacional de Colombia: AHNC), Archivo Restrepo, rolo 5, fol. 179. Veja também: Simón Bolívar, "A los pueblos de Venezuela", Guyana, August 5, 1817. In: Obras Completas. Madrid: 1960, 647; Simón Bolívar, "A los Soldados del Ejército Libertador”, October 17, 1817. In: Memorias del General O'Leary. Caracas: 1884. Vol. 15: 423-424.
} 
patriotas o vislumbre de uma nova era de igualdade racial republicana, livre do jugo espanhol. Discursos públicos, cerimônias de abolição e artigos de jornal recontavam uma história de despotismo e violência por parte da Espanha, que oprimia e dividia os compatriotas americanos. Já em 1817, Bolívar contrastava a igualdade racial republicana com o despotismo espanhol, sob o qual os pardos foram submetidos à suprema humilhação de serem privados de rigorosamente tudo. ${ }^{38}$

A Lenda Negra também ajudou na formação do comportamento em relação à escravidão durante o período. Diferentemente da igualdade racial, a abolição recebeu apenas uma mínima atenção em Cádiz. Grande parte dos deputados americanos tendiam a ignorar o tema, algo muito conveniente para eles. ${ }^{39}$ A Constituição de Cartagena de 1812 havia abolido o comércio de escravos, mas deixou a escravidão intocada. Por causa disso, a polêmica questão da escravidão ainda pairava sobre o novo estado independente quando a convenção se reuniu em Cucuta, em 1821. Em Cucuta, a libertação dos escravos se tornou o objeto de uma das discussões mais intensas e acaloradas. Ainda assim, deve ser enfatizado que nem mesmo o mais articulado dos senhores de escravo defendeu a escravidão como uma instituição. ${ }^{40}$ Era um acordo oficial que a escravidão pertencia ao passado e que uma nação moderna e iluminada como a Colômbia não deveria estar assolada pela escravidão. A questão era de como e quando a abolição iria acontecer. Após debates longos e passionais, o Congresso Constitucional decretou a Lei do Ventre Livre, que assegurou que mais nenhum escravo seria nascido na Colômbia. Os libertos (crianças nascidas de pais escravos após 1821) tinham que trabalhar para os donos de suas mães até que chegassem aos 18 anos, para que assim tivessem pagado o alegado custo de manutenção que os seus donos tiveram durante a fase de crescimento dos escravos. Somando-se a isso, o Congresso estabeleceu juntas de manumision com a intenção de acelerar o processo de abolição da escravatura através da criação de um fundo para comprar escravos nascidos ainda no cativeiro. A escravidão,

\footnotetext{
${ }^{38}$ Simón Bolívar, "A los pueblos de Venezuela," Guyana, August 5, 1817. In: Obras Completas, 647.

${ }^{39}$ Manuel Chust, La cuestión nacional, 102.

40 Jaime Jaramillo Uribe, "La controversia jurídica y filosófica, librada en la Nueva Granada en torno a la liberación de los esclavos y la importancia económica y social de la esclavitud en el siglo XIX", Anuario de Historia Social y de la Cultura.4 (1969): 76-80; Observaciones de G.T. sobre la ley de manumisión del soberano Congreso de Colombia. Bogotá: 1822. In: Colección de Libros Raros y Manuscritos Biblioteca Luis Angel Arango; "Los Hacendados y Vecinos de la Provincia de Cartagena de Colombia al Congreso", November 30, 1822, Archivo Legislativo del Congreso de Colombia, Cámara, Peticiones, t. 33, fols. 24-31.
} 
todavia, permaneceu legal ate 1852. Durante os debates constitucionais de 1821, a libertação dos escravos foi oficialmente declarada uma virtude nacionalista e republicana ${ }^{41}$ Uma medalha de Benemérito da Humanidade foi proposta para todos que libertaram mais do que 10 escravos. No calor dos debates, seis congressistas libertaram todos os seus escravos sob aplausos do público. O presidente do Congresso relatou que a Colômbia havia excedido em virtude as antigas repúblicas de Roma, Esparta e Atenas, por causa de seus representantes, que não se contentavam com um amor teórico a justiça, o que seria algo fácil, mas sim encontravam prazer em exercer os seus mandatos. ${ }^{42}$

Com a criação dos novos comitês de libertação dos escravos, o Estado colombiano estabeleceu um espaço crucial para a difusão das noções de raça, nação e cidadania. Historiadores têm caracterizado as juntas de manumision como instituições ineficientes que tentaram esconder a realidade nua e crua da escravidão. De fato, as comissões libertaram poucos escravos. ${ }^{43}$ Mesmo assim, elas foram importantes, não porque libertaram uma quantidade significativa de escravos, mas porque eles associaram a libertação com o nacionalismo colombiano, possibilitando, assim, a dicotomia entre os conceitos de escravidão com tirania espanhola e libertação com republicanismo. ${ }^{44}$

As celebrações do Dia da Independência na década de 1820 se constituíram em um espaço central na representação do rito de transformação dos escravos em cidadãos, bem como o nascimento da República. As leis obrigavam os comitês de libertação a libertarem escravos durante as festividades nacionais, fazendo dessas cerimônias uma parte essencial das celebrações. ${ }^{45}$ Por exemplo, em 1825, as festividades de independência em Cartagena começavam com um Te Deum, imediatamente seguido pela libertação de quatro escravos da junta de libertação no "Templo da Liberdade", um santuário esplendidamente decorado com colunas dóricas e uma cúpula coroada por um busto que representava a Liberdade. ${ }^{46}$ Estas cerimônias eram

\footnotetext{
${ }^{41}$ Actas del Congreso de Cucuta 1821. Bogotá: 1989. Vol. 1: 97

42 Actas del Congreso de Cucuta 1821 Bogotá: 1989. Vol. 1: 219-220.

${ }^{43}$ Harold A. Bierck Jr. "The Struggle for Abolition in Gran Colombia," HAHR 33, n. 3 (1953): 373-378; Margarita González. "El proceso de manumisión en Colombia," Cuadernos Colombianos 2 (1974): 196.

${ }^{44}$ Gaceta de Cartagena de Colombia, January 29, 1825.

${ }^{45}$ O Art. 12 da Lei de Manumissão de 19 de julho de 1821 decretava que as juntas poderiam alforriar escravos durante as celebrações nacionais. Actas del Congreso de Cúcuta 1821. Vol. 2: 52.

${ }^{46}$ Gaceta de Cartagena de Colombia, January 29, 1825.
} 
acompanhadas por discursos veementes que enfatizavam a natureza desprovida de fundamento da escravidão. No entanto, os colombianos se declaravam inocentes deste crime contra a humanidade. Apenas a violência e a ganância dos espanhóis eram responsabilizadas pela existência de escravos na América. A Colômbia concedeu aos escravos "La libertad que la naturaleza os concedió y La ambición de Europa os habia usurpado." ${ }^{47}$ Os colombianos orgulhosamente se consideravam um modelo a ser seguido: "En el teatro de las naciones [Colombia] aun se ensalza, filantropica como la primera, ilustrada como la que mas", proclamava um discurso de libertação. ${ }^{48}$ Um segundo elemento da fase inicial das noções nacionalistas de harmonia racial era a unidade. As primeiras autoridades republicanas acreditavam que eles possuíam a gigantesca tarefa de criarem uma nação unificada em uma região assombrada por divisões raciais e regionais. Como o libertador Simon Bolívar falou para os legisladores em Angostura, "Unidad, Unidad, Unidad debe ser nuestra divisa. La sangre de nuestros Ciudadanos es diferente, mezclemosla para unirla." ${ }^{49}$ Esta afirmação foi parte de uma dicotomia mais ampla, que privilegiava unidade sobre divisão, que tinha como inspiração a crença de Rousseau no antagonismo inerente entre unidade e fragmentação. ${ }^{50}$ As diferenças raciais estavam inseridas nessas noções. A questão da raça facilitava o surgimento de facções, o que tornava mais difícil a realização do sonho de uma sociedade governada por cidadãos virtuosos. Partindo dessa perspectiva, a noção de Pardocracia, trazida por Bolívar, representava o triunfo de uma facção em particular, a dos Pardos, sobre a unidade da nação. Na seqüência, se estabeleceu a perspectiva que a política racial representava um tipo de política que conduzia a divisão e, como tal, era uma ameaça para a nação. Enquanto a Colômbia continuasse a ser dividida por raça, a política virtuosa seria impossível. No princípio da ideologia republicana, cidadania e raça eram incompatíveis; a primeira defendia união e igualdade, a segunda representava divisão e antagonismo. Portanto, as

\footnotetext{
47 Gaceta de Cartagena de Colombia, January 29, 1825.

${ }^{48}$ Gaceta de Cartagena de Colombia, January 1, 1825.

49 "Discurso pronunciado por el Libertador ante el Congreso de Angostura el 15 de febrero de 1819"; Harold A. Bierck, Jr. Selected Writings of Bolivar. Translation by Lewis Bertrand. New York: Colonial Press, 1951. Vol. 2: 191-192.

${ }^{50}$ Jean Jacques Rousseau, The Social Contract and Discourses. New York: 1950, 26-28; Castro-Leiva. La Gran Colombia una illusion ilustrada. Caracas: 1985, 110, 125; Luis Castro-Leiva, "The ironies of the Spanish-American revolutions" International Social Science Journal 41, n. 1 (1989): 53-67; Hilda Sabato, "On Political Citizenship in Nineteenth-Century Latin America," AHR 106, n. 4 (2001): 1301.
} 
políticas raciais do período precisavam ser entendidas dentro da grande meta, que era eliminar qualquer causa que conduzisse ao conflito racial e a divisão, buscando assim incentivar o surgimento de uma nação de cidadãos, a qual seria uma nação de homens com valores e interesses idênticos.

Outro elemento da nova ideologia racial republicana era a mistura inter-racial entre europeus, negros e índios. Como podemos perceber, já em 1819, Bolívar estava propondo a obtenção de uma unidade nacional através da mistura racial. ${ }^{51}$ Esta mixagem como um caminho para a unidade nacional foi também um elemento importante de uma das primeiras histórias de independência da Grã Colômbia. Estabelecendo paralelos entre a Espanha e a América espanhola, o autor destaca como a expulsão dos muçulmanos não foi atingida pelos "nativos", mas sim por "una generación muy remota de sangre mezclada" "a quienes, sin embargo, nadie a disputado el derecho... a recobrar la independencia de su pais". O mesmo aconteceu, de acordo com o autor, na América espanhola, com a única diferença que "no hemos tenido tanto tiempo para batir los elementos heterogêneos y condensar la nueva masa". ${ }^{52}$ Diversos elementos dessa narrativa já apresentavam indícios da ideologia de mestiçagem que surgiria futuramente. Primeiramente, a noção de que as pessoas de descendência mista incorporavam a nação. Em segundo lugar, a idéia de que a mistura racial conduz a criação de uma nueva masa, um novo tipo de povo. Essa idéia poderia ser interpretada exclusivamente como tentativas racistas de eliminar a diversidade racial colombiana, mas isso seria de pouco proveito para nós compreendermos os valores políticos e ideológicos que davam coerência as primeiras políticas raciais republicanas. Diante disso, não é o objetivo afirmar que a elite era desprovida de preconceitos raciais, mas sim que as relações raciais tinham de ser compreendidas de uma forma mais ampla em relação às noções de cidadania existentes no período, que não podia imaginar diferença e diversidade em termos positivos. Nas palavras do intelectual pardo Garcia Del Rio, "heterogeneidad [a qual ele ligava a divisões de casta] es un principio malefico". Os colombianos poderiam apenas esperar pelos benefícios que tivessem efeito e "confunda nuestra poblacion". ${ }^{53}$ Para ele, bem como para outros intelectuais e políticos, imaginar os colombianos era imaginar cidadãos

\footnotetext{
${ }^{51}$ Harold A. Bierck Jr. Selected Writings of Bolivar. Vol. 2: 191-192.

52 "Independencia"; Gaceta de Cartagena de Colombia, n. 157 (1824): 2. The Gaceta de Cartagena published this history of independence in various segments.

${ }^{53}$ Citação extraída de Alfonso Múnera. Fronteras imaginadas, 148.
} 
com interesses e valores semelhantes. Por isso que, quando confrontados com cidadãos de diferentes cores, os primeiros legisladores podiam pensar tanto em termos de mistura, miscigenação e assimilação, como em termos de exclusão.

O relatório do Ministro do Interior Jose Manuel Restrepo, para o Congresso, em 1823, resumia a estratégia e os valores dos primeiros projetos republicanos para eliminar os conflitos raciais e promover a cidadania homogênea. Ele havia previsto que, no máximo em 60 anos, as castas iriam desaparecer e a Colômbia seria habitada apenas por homens livres. Por causa disso, uma das prioridades do novo governo era a passagem de leis que eliminavam as diferenças raciais através da união física e cultural, a qual eles esperavam que gradualmente eliminasse o legado do conflito e da divisão racial. ${ }^{54}$ Como parte da sua política para promover a igualdade legal, o novo governo central eliminou a identificação racial dos arquivos do Estado. ${ }^{55}$ A lei do nascimento livre foi também apresentada dessa maneira. Mesmo que Restrepo reconhecesse os problemas econômicos que poderiam derivar da Lei do Ventre Livre, ele falou para os legisladores que a lei era um mal menor, se comparada com a inevitável guerra racial que se seguiria com a manutenção da escravidão. ${ }^{56}$ Por fim, a educação era outro pilar do programa estatal para criar uma nação de (homogêneos) colombianos, oriundos de uma população "racialmente" diversificada. ${ }^{57}$

Em torno de 1820, a harmonia racial havia se tornado tão parte do nacionalismo colombiano que negar essa aspiração era a mesma coisa que se opor ao republicanismo ou apoiar a monarquia espanhola. Contudo, não podemos negar que algumas pessoas se opuseram a essa noção, justamente como alguns lembravam com nostalgia a paz e a ordem do jugo espanhol e buscavam restabelecer o domínio monárquico. Entretanto, expressar tais noções publicamente envolvia certo custo político e pessoal.

O consenso político sobre as virtudes da igualdade racial não significava um acordo sobre as implicações concretas que esta nova igualdade teria tido nas relações políticas e sociais das cidades

\footnotetext{
${ }^{54}$ José Manuel Restrepo, "Memoria que le secretario de estado y del despacho del interior presentó al Congreso de Colombia sobre los negocios de su departamento. Año de 182313". Biblioteca Nacional de Colombia, Miscelánea, n. 1.160.

${ }_{55}$ David Bushnell. The Santander Regime in Gran Colombia. Newark: 1954, 173.

${ }^{56}$ Restrepo. "Memoria que le secretario de estado,"14-15; Simón Bolívar. Proclamas y Discursos, 232 and 332.

57 David Bushnell. The Santander Regime, 183-193. Session of May 16, 1823, Santander y el Congreso de 1823: actas correspondencia, senado. Bogotá: 1989. Vol. 3: 67-68.
} 
colombianas. Esta falta de consenso foi complicada ainda mais pela instabilidade política e social que caracterizava os anos da guerra. Mudanças na composição da elite política e militar parecia inicialmente apoiar as novas noções de cidadania e igualdade racial. As autoridades espanholas foram substituídas pelas autoridades crioulas, que às vezes incluíam pardos, que haviam sido promovidos para posições políticas e militares importantes durante a guerra. Além do mais, em regiões costeiras, como Cartagena, os pardos levaram a sério as declarações de igualdade do governo e, ativamente, denunciaram situações de discriminação racial. Mesmo que a escravidão continuasse sendo legal, estava bastante desgastada pelas guerras. Na província de Cartagena, o número de escravos caiu $50 \%$ durante as guerras de independência. ${ }^{58}$ Os escravos que se juntaram ao exército patriótico estavam agora legalmente livres e escravos que viviam nas inúmeras haciendas foram abandonados por seus donos durante as guerras e haviam já se acostumado com a liberdade..$^{59}$

Nada expressava melhor a instabilidade social do período e as ansiedades da elite racial como os rumores de guerra racial. Referências à guerra racial (guerra de colores) era uma parte integral do discurso político nos primórdios da Colômbia republicana. O vice-presidente Santana escreveu para o Ministro do Interior sobre a necessidade de criar efetivas leis criminais para lidar com os negros que estavam desenvolvendo projetos de dominação. ${ }^{60}$ De forma similar, em 1823 , o Ministro do Interior, Jose Manuel Restrepo, mencionou, em vários trechos de seu diário, uma série de conspirações contra os brancos. Ele ponderava, "Es muy probable, y El Libertador siempre lo pronostica, que concluida la guerra con los españoles tengamos otra con los negros." 61 Nas suas sessões secretas, o senado, em 1823, discutiu os perigos que as diferenças raciais representavam para a República. ${ }^{62}$

${ }^{58}$ Veja-se os censos para a província de Cartagena em 1780 e 1825 em Hermes Tovar Pinzón, Convocatoria al poder del número: censos y estadísticas de la Nueva Granada 1750-1830. Bogotá: 1994.

${ }^{59}$ Cartagena, March 1816, AGI, Cuba 717Archivo Legislativo del Congreso de Colombia, Senado, Consultas, t. 58, fols. 28, and 45-47. For the impact of the war of independence on slave soldiers, see Peter Blanchard, "The Language of Liberation", 499-523; Bierck, Harold A., Jr. "The Struggle for Abolition in Gran Colombia", 365-386.

${ }^{60}$ Francisco de Paula Santander to the Minister of Interior, September 7, 1824, Archivo Legislativo del Congreso de Colombia, Senado, Consultas, t. 58, fols. 43-44.

${ }^{61}$ José Manuel Restrepo, 23 March 1823, Diario político y militar: memorias sobre los sucesos importantes de la época para servir a la historia de la Revolución de Colombia y de la Nueva Granada, desde 1819 para adelante (Bogotá, 1954) vol.1: 211.

${ }^{62}$ Senateto Santander, 7 June 1823, Santander y el Congreso de 1823, vol. 1: 309. 
O medo da guerra racial não era apenas uma preocupação da presidência, do senado e de outras autoridades centrais em Bogotá, mas também era uma constante preocupação entre as elites locais. Em junho de 1831, Juan Barbosa, um passageiro viajando de Cartagena até Kingston, escreveu em seu diário uma longa discussão de grande transcendência entre marinheiros sobre uma "conspiración de negros en Colombia." Dois dias depois, ele escreveu novamente, "ayer volvio a promoverse La conversión en la tripulacion...Esta conversacion es promovida por cualquiera de los marineros colombianos diciendo que en Colombia vendra a ser como la Isla de Santo Domingo." ${ }^{63} \mathrm{O}$ registro de Barbosa não era o único. Não foi a primeira vez e, nem seria a última, que as autoridades colombianas receberiam inúmeras denúncias sobre possíveis guerras raciais e conspirações do mesmo tipo. De 1811 a 1828, os rumores de uma guerra racial apareceram durante os julgamentos de pardos politicamente ativos em Honda, Majagual, Mompox e Cartagena. Em 1832, boatos de guerra racial surgiam novamente na Colômbia caribenha. Em janeiro, dois homens foram executados na cidade de Santa Marta, por conspiração contra os brancos, enquanto os seus cúmplices foram banidos da região. ${ }^{64}$ No mesmo mês, outro pardo foi executado em Mompox, por conspirar o começo de uma revolução de pardos, enquanto um homem e uma mulher foram banidos por não denunciarem a conspiração. ${ }^{65} \mathrm{Na}$ mesma época, os rumores de guerra racial se espalharam em Cartagena, mas o governador não achou nenhuma conspiração. Contudo, ele baniu um pardo por dois anos, Agustín Martinez, que estava sendo acusado de escrever e imprimir um panfleto sedicioso contra os brancos. ${ }^{66} \mathrm{Um}$ ano depois, 50 artesãos pardos foram denunciados por conspiração contra os brancos em Cartagena. ${ }^{67}$

Que nenhuma dessas conspirações tenha resultado em uma rebelião de raça não diminui a sua relevância histórica. Bem pelo contrário, elas representam um questionamento importante; porque esses rumores eram tão presentes no período e, o que eles nos dizem sobre os medos e as expectativas existentes naquela época e, também, quando e porque eles tinham maior probabilidade de acontecer? Além do possível impacto que

\footnotetext{
${ }^{63}$ Ministerio de Interior, t. 1, fol. 155, República, AHNC.

${ }^{64}$ AHNC, República, Ministerio de Interior, t.1, fols. 154 and 163.

${ }^{65}$ AHNC, República, Ministerio de Interior, t. 1, fols. 5-32

${ }^{66}$ AHNC, República, Gobernación de Cartagena, t. 42, fols. 2-8; AHNC, República, Ministerio de Interior, t. 1, fols. 99-105.

${ }^{67}$ AHNC, República, Ministerio de Interior, t.1, fol. 351-353.
} 
os rumores possam ter tido nas construções raciais republicanas. Uma análise das circunstâncias políticas cercando os boatos de guerra racial revela que eles surgiram em momentos fundamentais da revolução, quando a extensão e o significado da mudança revolucionária e sua influência sobre as relações de poder entre brancos e negros estava em jogo. Em alguns casos, os rumores de guerra racial ocorreram quando os pardos alcançaram posições de autoridade local e tentaram impor a sua autoridade sobre a elite branca local. Isto é evidente, por exemplo, no julgamento criminal contra o juiz pardo Valentin Arcia pela sua "aversão criminal contra os brancos." De acordo com o juiz Arcia, a elite o acusava apenas porque "como soy la clase de pardos, les incomodo verme de juez y que ellos estuviesen bajo de mi mando." ${ }^{68}$ De fato, os detalhes das acusações contra Arcia revelam uma luta intensa sobre a possibilidade de um carpinteiro pardo ser sido capaz de impor a sua autoridade sobre a elite local. Com relação às tentativas de elite de ignorar e diminuir a sua autoridade, Arcia respondeu ao publicamente denunciar a discriminação racial e ao alertar a elite local do perigo que representava a continuidade de práticas tão pouco republicanas. ${ }^{69}$ Portanto, o caso de Arcia, como em outros casos onde pardos influentes foram acusados de inimizade sediciosa com relação aos brancos, revelam conflitos entre brancos e pardos sobre as implicações que o seu novo poder iria gerar sobre as relações sociais locais. ${ }^{70}$

Outros rumores raciais coincidiram com grandes mudanças políticas, como o estabelecimento de juntas revolucionárias crioulas ou o chamado de convenções constitucionais. Estas se constituíam em verdadeiros momentos fundamentais para a era revolucionária, onde tais noções como tirania, anarquia, demagogia, igualdade e liberdade, bem como as suas implicações raciais e sociais, foram debatidas de uma forma bastante passional. Por exemplo, os rumores de guerra racial apareceram

68 "Causa criminal contra Valentin Arcia, alcalde ordinario de segunda nominación de Majagual por hablar mal contra los blancos y contra el gobierno," AHNC, República, Archivos Criminales, t. 61, fols.1143-1209, and AHNC, República, Archivos Criminales, t. 96 , fols. 244-322.

69 "Causa criminal contra Valentin Arcia AHNC, República, Archivos Criminales, t. 61, fols.1143-1209, e AHNC, República, Archivos Criminales, t. 96, fols. 244-322.

${ }^{70}$ Uma análise acurada desses julgamentos e do julgamento de Arcias podem ser encontrados em Marixa Lasso, "Haiti as an Image of Popular Republicanism in Caribbean Colombia, Cartagena Province (1811-1830)" in David Geggus (ed.) The International Impact of the Haitian Revolution in the Atlantic World (Charleston S.C., 2001) and Marixa Lasso, "Race and Republicanism in the Age of Revolution, Cartagena 1795-1831" (Ph.D. dissertation, University of Florida, 2002). Para uma interpretação posterior e diversa do caso Padilla, veja: Aline Helg, Liberty \& Equality, 195-223. 
durante a primeira república de Cartagena, quando o congresso se reuniu para eleger o governador em 1814. Conflitos entre as duas facções locais sobre quem seria o novo mandatário local deu surgimento aos rumores sobre uma conspiração parda para colocar um dos seus como governador. ${ }^{71}$ Rumores de guerra racial também apareceram durante a convenção de Ocana em 1828, quando os pardos se opuseram ao projeto constitucional bolivariano e denunciaram instâncias de discriminação racial. $^{72}$ Novamente, em 1831, tentativas por parte de liberais radicais locais de redefinir as relações de poder em Cartagena estavam inseridas em uma linguagem de guerra racial. Em resumo, os rumores de guerra racial coincidiram com o momento onde as mudanças políticas locais e nacionais promoveram conflitos e negociações bastante árduas sobre relações raciais, sociais e políticas. ${ }^{73}$

Por trás das alegadas conspirações raciais estava a pressão dos pardos para forçar a elite a cumprir as suas promessas de igualdade racial. Mesmo que os pardos tenham concordado com a elite política nas virtudes e no desejo de harmonia racial e igualdade, eles tiveram uma perspectiva bem diferente sobre a realidade do ideal republicano no período. Em contraste com a elite, eles acreditavam que a sua luta política por igualdade racial havia acabado. Repetidas vezes, os pardos reclamavam sobre práticas persistentes de discriminação racial. A linguagem a qual eles expressavam as suas queixas pode ainda ser plenamente apreciada nas seguintes denúncias satíricas da discriminação social em um café de Cartagena, onde um artesão pardo publicou um panfleto impresso. ${ }^{74}$

\section{AVISO}

En la café, bollería y garito del Señor Cayetano Corrales, sita en la calle de San Agustín, se admite al dinero de todo el que tenga

\footnotetext{
${ }^{71}$ José Salvador de Narváez, "Operaciones del Ejército de Cartagena situado en la línea occidental del río Magdalena, desde el 22 de diciembre de 1814 hasta el 18 de enero de 1815, con motivo de lo ocurrido en el Colegio electoral y Revisor el 17 de Diciembre citado," 30 January1815, in Manuel Ezequiel Corrales, Efemérides y anales del Estado de Bolivar (Bogotá, 1889) vol. 2: 172-176. Pedro Gual, "Primer oficio del gobernador de la provincia de al secretario del Estado y Relaciones Exteriores del Gobierno de la Unión, January 30, 1815," AHNC, Restrepo, rollo 5. fols. 115-116.

72 "Cartagena, Sumaria averiguación para aclarar asuntos relacionados con la seguridad pública y con la subordinación y disciplina en las clases del ejército," AHNC, República, Archivos Criminales, t. 44, fols. 86-118

${ }^{73}$ Análise do contexto desses casos está aprofundada em Marixa Lasso, "Race and Republicanism during the Age of Revolution," 89-201.

74 AHNC, República, Gobernación de Cartagena, 42, fol. 5.
} 
la necesidad de ir allí a gastarlo; pero solamente tienen derecho a tomar asiento, tertuliar, jugar los triqs y las barajas, entrar, salir endonde quiera y como gusten los señores de alta categoría; (pues, aquellos que llaman blancos) bien porque tienen dinero, o bien porque son procedentes de la sangre azul. Un artesano honrado, decente y hombre de bien si carece de aquellas eminentes cualidades y circunstancias, que largue los reales, bueno; pero debe también largarse luego, porque detenerse un punto en la asamblea de tan distinguidísimos señores, es un sacrílego atrevimiento. Viva la aristocracia, viva el envanecimiento de fatuos y mentecatos como el Sr. Corrales, y muera el que sin ser blanco [cursilla en el original] ni tener sangre azul, plata o charreteras tenga la poca vergüenza de ir a darle provecho, y a la vez motivo a que le desprecien y lo insulten si se detiene.

UN PARDO HONRADO

Este panfleto segue a linguagem das queixas raciais vociferadas pela maioria dos pardos, acusados de animosidade racial contra os brancos. Uma característica saliente do panfleto é a sua ênfase na natureza aristocrática da desigualdade racial, que era um tema recorrente nos primórdios da igualdade racial republicana. A discriminação contra os pardos honestos era um sinal do comportamento aristocrático. $\mathrm{O}$ panfleto contrastava a vaidade, o sangue azul e o alto status daqueles que discriminavam os pardos com a decência dos artesãos vitimizados, que incorporavam os valores republicanos de trabalho e honestidade. Em seguida, o autor estava querendo ligar termos raciais e identificação. Ele associava as categorias pardo e branco com valores aristocráticos que deveriam pertencer ao passado. Contudo, porque as suas experiências lhe diziam que elas não eram ainda algo do passado, ele publicamente as utilizou para expor a discriminação. Ele não queria enterrar e silenciar o tema raça, enquanto esta continuasse a ser utilizada para discriminar os pardos. Por isso, o pardo honesto falava abertamente contra os brancos arrogantes que se recusavam a sentar com os pardos em um de seus cafés. As autoridades judiciais de Cartagena declararam que o panfleto assinado por um pardo honrado a "impreso subversivo" e o autor, Augustin Martinez, foi acusado de sedição e acabou banido por dois anos. Ele aprendeu da maneira mais dura que era perigoso procurar reparação pública da histórica discriminação racial. ${ }^{75}$

${ }_{75}$ AHNC, República, Ministerio de Interior, t. 1 fol. 102. 
A experiência de Martinez não era única. Outros pardos que desejavam denunciar a discriminação racial encontravam problemas similares. Isso pode ser verificado entre um grupo de artesãos, que haviam se reunido para celebrar um batismo. Eles discutiram a discriminação contra os pardos, que era realizada pelas autoridades locais. Por exemplo, um deles declarou, "que si un blanco tenía un pleito o le jugaba a un negro una herida siempre al negro lo metían en la cárcel y que con todo que conocieran la razón echaban al negro al presidio y el blanco se quedaba riendo." ${ }^{176}$ Outro disse aos seus companheiros artesãos que as suas dificuldades econômicas eram causadas pelas ações de oito ou dez brancos. ${ }^{77}$ Como resultado, cinqüenta deles foram presos por tentarem "robar asesinar y tal vez destruir el gobierno." Quando o governo decidiu que a alegada conspiração era meramente um ato de embriaguez, eles foram libertados. ${ }^{78}$ Outros tiveram menos sorte. Alguns pardos que enfrentavam acusações similares foram executados, outros foram banidos, e outros foram apenas libertados após julgamentos longos e dolorosos. As denúncias políticas dos pardos, que eram qualificadas como tentativas acertadas de impor a lei republicana sobre a elite despótica, estavam agora apresentadas como tentativas sujas na busca da promoção da guerra racial. Julgamento após julgamento, a mensagem de que a exposição pública de queixas raciais era algo perigoso e poderia levar a conseqüências políticas e pessoais fatais estava sendo reforçada. ${ }^{79}$

Os casos criminais contra os pardos acusados de sedição ou animosidade racial demonstravam os mecanismos pelos quais as autoridades locais apresentavam as queixas raciais em uma linguagem belicosa. As testemunhas pertencentes à elite revelavam não apenas a sua relutância em aceitar os pardos com poder político - dificilmente uma reação surpreendente -, mas também a sua dificuldade em expressar o seu antagonismo. Eles não podiam acusar abertamente os pardos de não saberem o seu lugar, ou, de não respeitarem as suas hierarquias naturais, porque tais noções estavam agora declaradas como antinacionais e despóticas. Ainda assim, ao retratarem as denúncias dos pardos de discriminação racial e ao desafio a autoridade da elite como animosidade

\footnotetext{
${ }^{76}$ AHNC, República, Ministerio de Interior, t. 1, fol. 353.

77 AHNC, República, Ministerio de Interior, t. 1, fol. 353.

${ }_{78}$ AHNC, República, Ministerio de Interior, t. 1, fol. 351-353.

79 Para uma análise detalhada de inquéritos criminais contra pardos em Cartagena durante a primeira década da Independência, ver Marixa Lasso, "Race and Republicanism in the Age of Revolution."
} 
racial, a elite branca objetivava expurgar as ações dos pardos da esfera do que era considerado legítimo na esfera política.

Elites locais se referiam à harmonia racial como algo que já havia sido atingido. Eles descreviam as suas cidades como lugares onde a paz racial e a harmonia reinavam, o que tornava qualquer outra mudança desnecessária e qualquer referência a raça sem sentido. Essa retórica deixou pouco espaço restante, ou nenhum sequer, para queixas raciais. A acusação contra o juiz Arcia provém um claro exemplo de como essa retórica foi utilizada. O diálogo escrito pelo juiz Arcia sobre a persistência da discriminação racial e social na sua cidade lhe rendeu a acusação de promoção sediciosa da guerra racial. ${ }^{80} \mathrm{O}$ seu complexo conflito com a elite branca local poderia ser resumida dessa forma: "él no cesa de declamar contra la clase de individuos blancos, sin reflección de que todos somos miembros indistintos de la sociedad. El se ha propuesto dividir el maridaje en que este vecindario tranquilo ha reposado inspirando una aversión criminal contra los blancos." ${ }^{81}$ Já que a harmonia e a igualdade estavam presentes, as reclamações raciais de Arcia poderiam ser consideradas apenas como uma manifestação de sua aversão contra os brancos.

Uma vez declarada desnecessária, a queixa racial se tornou uma tentativa perigosa de perturbar a ordem pública. Por isso, a elite branca atribuía qualquer expressão de conflito racial a má influencia de figuras nefastas que visavam quebrar a união, a paz e a tranqüilidade das cidades. Ao associar as queixas raciais com guerra racial, autoridades locais as inseriram dentro de um discurso geral de revolta e sedição. Mas, vamos retornar ao "pardo honesto." Ele foi acusado e condenado pelas suas "declarações alarmantes e ameaçadoras contra o governo," e pela "tentativa de provocar uma comoção popular com o seu panfleto." Ele foi também acusado de espalhar "idéias sediciosas" contra o governo, idéias capazes "de incitar a rebelião ou, no mínimo, perturbar a ordem pública." O seu acusador afirmou que desde que a publicação do panfleto a cidade "estava em constante alarme, temendo uma insurreição a qualquer momento." 82

Desta forma, a elite invertia as noções de vitimização. Os pardos deixaram de ser as vítimas de discriminação e se tornaram agentes na promoção do ódio entre as raças, enquanto as elites deixaram de ser

\footnotetext{
${ }^{80}$ AHNC, República-Archivos Criminales, t. 96, fols. 244-322.

${ }^{81}$ AHNC, República-Archivos Criminales, t. 61, fols.1143-1209.

${ }^{82}$ AHNC, República, Ministerio de Interior, t. 1, fol. 102.
} 
os defensores da hierarquia racial e se tornaram as vítimas do ódio racial. Além disso, a noção de queixa racial não encontrava espaço em um discurso de elite que declarava a igualdade como algo já atingido. $\mathrm{O}$ discurso das autoridades não deixava espaço entre harmonia racial e guerra, onde as queixas raciais tinham de se encaixar ou em uma categoria, ou em outra. Através de sua associação com guerra racial e sedição, debates abertos sobre raça e identificação racial se foram marcados como algo que se opunha ao patriotismo e ao nacionalismo e, por isso, foi expurgado do discurso público considerado legítimo. Em resumo, conversas explícitas sobre raça foram não apenas criminalizadas pelas elites locais, mas também foram transformadas em uma tentativa sediciosa de perturbar a harmonia e a ordem pública.

O discurso nacionalista de harmonia racial foi ainda mais consolidado pelos meios onde os atores locais - pardos e elite - se relacionavam com o Estado central. Nem as autoridades locais e tão pouco os pardos poderiam ter o apoio do Estado central dado como certo. Nem todos os pardos foram considerados culpados pelas autoridades centrais. Em alguns casos, o Estado central não apenas declarou os pardos inocentes, mas acabou transferindo a acusação para a elite local. ${ }^{83} \mathrm{Em}$ outros casos, eles rejeitaram a alegada gravidade que o discurso racial dos pardos poderia representar. Em um caso, o Secretário do Interior não apenas desmentiu a alegada severidade do discurso racial dos pardos, como apenas um ato inconseqüente de embriaguez, mas também lembrou ao governo de Cartagena que "es tan importante como justo" assegurar que apenas uma administração equilibrada da justiça eliminaria qualquer resíduo dos velhos ressentimentos raciais entre diferentes setores da população. ${ }^{84}$

O sucesso na obtenção de uma decisão favorável das autoridades centrais dependia em grande parte da habilidade dos atores em demarcarem a sua posição de acordo com os legítimos princípios republicanos. Era particularmente importante que eles demonstrassem o seu apoio para a igualdade racial e para a ordem pública. Essa tática é nítida na resposta das elites às denúncias dos pardos relacionadas à desigualdade racial. As autoridades locais tinham de convencer o Estado do seu êxito na promoção de igualdade e harmonia racial nas suas cidades. Por isso, cada vez que um pardo levantava a questão da

\footnotetext{
${ }^{83}$ Vejam-se os casos do supracitado senador Remigio Márquez e de Buenaventura Pérez em AHNC, Anexo, Guerra y Marina, 106, fols. 445-477.

${ }^{84}$ AHNC, República, Ministerio de Interior, t. 1, fol. 351.
} 
discriminação racial, além da repressão e do silêncio que lhe era imposto, as elites locais também tinham de reiterar o seu comprometimento público com a igualdade racial. O estado central possuía um papel vital na consolidação das queixas raciais em um tabu. E o fez não apenas reprimindo ainda mais os pardos, mas também ao defender a noção de harmonia racial; ao forçar as recalcitrantes elites locais a tolerarem um maior grau de igualdade racial do que eles sequer estariam dispostos a aceitar, a ficção da harmonia estava mantida.

As Guerras Americanas de Independência levantaram algumas questões cruciais sobre o impacto das lutas anticoloniais no desenvolvimento do imaginário racial nas Américas. Elas sugerem que a identidade nacional foi construída em oposição aos inimigos imperialistas e que tiveram um grande impacto no futuro das relações raciais. Uma breve tentativa de comparação entre os Estados Unidos e a Colômbia traz à tona este ponto de vista. Em ambas as regiões, o nacionalismo patriótico exaltava as diferenças entre a tirania das metrópoles européias e a liberdade das repúblicas americanas. Mesmo assim, o lugar da raça na equação da liberdade dependia menos nas noções que os patriotas possuíam sobre a própria liberdade - a qual, depois de tudo, se inspirou em dada medida na tradição iluminista - do que da postura que o poder colonial os condicionava neste tema. Em outras palavras, ela dependia de que a igualdade racial fosse percebida como uma imposição colonial ou como uma aspiração patriótica. Nos Estados Unidos, a propagada de guerra apresentou a Inglaterra como a "defensora" dos direitos dos "negros." Como argumentou John Sweet, um dos "piores pesadelos dos colonos era o prospecto de serem rebaixados a igualdade com os negros ${ }^{85}$ Estes sentimentos eram muito similares aos dos brancos colombianos e venezuelanos, que em 1790 denunciaram o apoio espanhol as milícias negras como um claro sinal de desrespeito ao bem estar dos súditos da América espanhola. Ainda assim, as guerras de independência na América espanhola inverteram essas noções. A propaganda patriótica agora denunciava duramente a oposição "autocrática" dos espanhóis aos direitos de representação dos negros.

A associação divergente entre o nacionalismo dos patriotas e a raça se desenvolveu durante as guerras e teve uma enorme influência na construção dos imaginários modernos em ambas as regiões. $\mathrm{O}$ nacionalismo iria determinar se a igualdade racial se tornaria um elemento

$\overline{85}$ John Wood Sweet, Body Politics, 191. 
vital da ideologia nacional, como na Colômbia, ou um conceito precário, constantemente submetido a uma série de desafios, como nos Estados Unidos. Na Colômbia, a revolução havia transformado a igualdade racial de uma posição política entre outras tantas, em um inquestionável princípio nacionalista. Isso ocorreu porque, apesar das inúmeras guerras civis e mudanças constitucionais que conduziram a Colômbia a oscilar constantemente entre o federalismo e o centralismo e do Sufrágio Universal ao voto censitário, o princípio da igualdade racial nunca foi questionado. Nos Estados Unidos, a igualdade racial era apenas uma entre outras posições respeitáveis, como o apoio a programas que enviassem os negros de volta à África. Poucos eventos representaram tão bem a desconexão entre nacionalismo e igualdade racial como as celebrações do Quatro de Julho nos anos 1820 a 1830, quando negros livres foram agredidos e expulsos nas celebrações por turbas raivosas que clamavam que a data "pertencia exclusivamente a raça branca." 86 Até mesmo em um nível simbólico, a Revolução Americana falhou em inaugurar uma nova era nas relações raciais. Isso explica porque até mesmo hoje em dia é difícil encontrar um ícone estadunidense nacionalista, que, como Simon Bolivar, pode reclamar para si a lealdade de uma nação inteira. A luta pela igualdade racial nos Estados Unidos estava ligada aos sangrentos conflitos regionais e, não a uma frente unificada contra um inimigo comum. Não seria até outra guerra - contra outro inimigo - na década de 40, que as construções raciais que se desenvolveram no período revolucionário seriam questionadas com êxito.

As lutas modernas para extinguir a desigualdade racial formal e informal nos Estados Unidos e na América espanhola teriam de ser confrontadas com a associação conflitante entre nacionalismo e igualdade racial, que surgiu no período revolucionário. Nos Estados Unidos, os negros iriam ser excluídos do imaginário nacional e a igualdade racial no plano jurídico lhes seria negada; ainda assim, eles iriam formar organizações poderosas e duradouras, que iriam lidar efetivamente com a luta contra o preconceito formal e informal. Na América espanhola, os negros iriam gozar de igualdade legal e, até mesmo, algumas vezes, fariam parte do imaginário nacional que aclamava o mulato como a incorporação da nação. Ainda assim, ao mesmo tempo, eles iriam

\footnotetext{
${ }^{86}$ Leonard I. Sweet, "The Fourth of July and Black Americans in the Nineteenth Century: Northern Leadership Opinion within the Context of Black Experience," in Journal of Negro History 61, no 3 (1976):.258-259; Shane White, “'It was a Proud Day:' African Americans, Festivals, and Parades in the North, 1741-1834," in The Journal of American History, 81 (1994): 38-41.
} 
enfrentar grandes dificuldades ao lutarem contra o preconceito informal, em um ambiente que havia feito da denúncia do racismo um tabu e as organizações negras como um sinal de comportamento divisivo e antipatriótico.

Solicitado em 15/12/2009. Aprovado em 29/11/2010. 